\title{
Integere relaties: wetenschappelijke integriteit en de verhouding tussen wetenschap en samenleving ${ }^{*}$
}

\author{
Esther Turnhout ${ }^{* *}$
}

Wetenschap staat onder druk. Dat lijken althans wetenschappers zelf in groten getale te vinden. Wetenschap moet haar autoriteit en geloofwaardigheid terugkrijgen, zichzelf opnieuw uitvinden en ze moet haar publieke functie in de democratie weer gaan vervullen. Hoewel de verschillende bijdragen aan het debat hierover allemaal het huidige wetenschapssysteem bekritiseren, is het belangrijk om te beseffen dat ze niet allemaal hetzelfde zeggen of dezelfde doelen voor ogen hebben. Sommigen lijken vooral uit te zijn op het (her)winnen van respect en autoriteit voor de wetenschap (Nurse, 2012; Van Dijck \& Saarloos, 2017). Anderen uiten kritiek op de over-gemanagede universiteit en de nadruk op kwantitatieve prestatie-indicatoren (Benedictus, Miedema \& Ferguson, 2016; Halffman \& Radder, 2013). Weer anderen leggen de nadruk op de relatie tussen wetenschap en samenleving en suggereren dat het tijd is voor een nieuw contract tussen wetenschap en samenleving (Gibbons, 1999; Sarewitz, 2016).

In dit essay richt ik me op dit laatste onderwerp: de relatie tussen wetenschap en maatschappij. Ik geef eerst een overzicht van dominante idealen over hoe deze relatie het beste kan worden georganiseerd en van de kritiek die is geuit tegen deze idealen. Vervolgens illustreer ik, aan de hand van een voorbeeld over statiegeldonderzoek, de risico's en knelpunten die kunnen optreden als niet zorgvuldig wordt nagedacht over welke rol wetenschap in verschillende vraagstukken kan spelen. Op basis daarvan pleit ik voor een verbreding van het begrip 'wetenschappelijke integriteit', zodat die niet alleen betrekking heeft op het gedrag van individuele wetenschappers, maar ook op de institutionele relaties en maatschappelijke context waarin wetenschappers handelen.

\section{Autonomie, overmoed en impact}

Idealen over de relatie tussen wetenschap en beleid stellen verschillende principes centraal. Een van de meest bekende idealen is het zogenaamde lineaire model. Volgens dit model biedt goed gefinancierde en autonome fundamentele wetenschap de beste garanties voor maatschappelijke en economische vooruitgang. In een invloedrijk rapport formuleert Bush (1945) dit ideaal als volgt:

* Met dank aan Herman Eijsackers voor zijn zorgvuldige en constructieve opmerkingen.

** Prof. dr. Esther Turnhout is werkzaam bij de Forest and Nature Conservation Policy Group, Wageningen Universiteit. 
'Scientific progress on a broad front results from the free play of free intellects, working on subjects of their own choice, in the manner dictated by their curiosity for exploration of the unknown.'

Dit ideaal is gebaseerd op een strikte scheiding tussen enerzijds de productie van kennis in het domein van de wetenschap en anderzijds het gebruik van die kennis door beleid, politiek en andere maatschappelijke en private actoren. Dit ideaal van wetenschap als autonoom en zelfregulerend komt regelmatig terug. Onder andere in Polanyi's (1962) analyse van 'the republic of science' waarin hij stelt dat wetenschap functioneert als een ideaal voor een vrije samenleving: 'In the free cooperation of independent scientists, we shall find a highly simplified model of a free society.' En: 'Any attempt at guiding scientific research towards a purpose other than its own is an attempt to deflect it from the advancement of science.'

Recente uitingen van dit model zijn te vinden in Van Dijck en Saarloos (2017): 'In 2017, hebben we, meer dan ooit, wetenschappers nodig als hoeders van feitelijkheid' en 'een cultuur zonder gezamenlijke feiten kan zomaar veranderen in een samenleving waarin iedereen zijn eigen mening onderbouwt met zijn eigen feiten - een emocratie in plaats van een democratie'. En in Nurse (2012): 'The scientific endeavour is at its most successful when there is freedom of thought' en 'we should reawaken the spirit of the Enlightenment, a respect for science and rationality...'.

Deze laatste twee uitspraken echoën het verlichtingsideaal van de zeventiende eeuw, waarin de wetenschappelijke methode niet alleen werd gezien als een voorwaarde voor wetenschappelijke vooruitgang, maar ook als een voorwaarde voor vrijheid, vooruitgang, vrede en democratie (Shapin \& Schaffer, 1985). ${ }^{1}$

Hoewel, zoals het bovenstaande laat zien, het lineaire model nog altijd voor velen een aantrekkelijk ideaal is, is dit model veelvuldig bekritiseerd. Recent nog door Sarewitz (2016), die beargumenteert dat juist de autonomie van de wetenschap, die volgens het lineaire model de beste garanties zou moeten bieden voor vooruitgang, ervoor heeft gezorgd dat wetenschap de relatie met de maatschappij uit het oog heeft verloren:

'Advancing according to its own logic, much of science has lost sight of the better world it is supposed to help create. Shielded from accountability to anything outside of itself, the "free play of free intellects" begins to seem like little more than a cover for indifference and irresponsibility. The tragic irony here is that the stunted imagination of mainstream science is a consequence of the very autonomy that scientists insist is the key to their success.'

Zijn diagnose van het huidige wetenschapssysteem, waarin wetenschappelijke vooruitgang bestaat uit de productie van feiten die vooral naar andere feiten verwijzen, bouwt voort op Weinbergs (1972) concept 'trans-wetenschap'. Weinberg definieerde dit begrip om aan te geven dat sommige vragen die in de wetenschap worden gesteld, en ook worden gezien als wetenschappelijk, eigenlijk niet te beantwoorden zijn, bijvoorbeeld door praktische en technologische beperkingen 
of doordat het object van kennisvergaring geen eenduidige definitie heeft. Om met dat soort vragen om te gaan pleit Weinberg voor een attitude van onbaatzuchtige eerlijkheid en bescheidenheid. In dergelijke vraagstukken moet wetenschap haar beperkingen erkennen en de dialoog met de maatschappij aangaan. ${ }^{2}$ En dit is precies waar het wat betreft Sarewitz (2016) mis is gegaan: in plaats van onbaatzuchtigheid, eerlijkheid en bescheidenheid over de beperkingen van wetenschap in trans-wetenschappelijke vraagstukken heeft de wetenschap deze vraagstukken juist in het eigen domein getrokken. Daarmee heeft het verwachtingen gewekt over wat wetenschap vermag waar het niet aan zal kunnen voldoen. Dit is overmoed (Jasanoff 2003).

Deze overmoed wordt niet alleen binnen de wetenschap maar ook daarbuiten gecultiveerd en in stand gehouden. De maatschappij verlangt van wetenschappers dat ze problemen oplossen, impact pathways identificeren en handelingsopties ontwikkelen. De financiering van onderzoek is in belangrijke mate gebaseerd op het principe van maatschappelijke impact. Zo houden wetenschap en samenleving elkaar gevangen in een onhoudbaar verhaal waarin feiten en waarden van elkaar te scheiden zijn en waarin wetenschappelijke kennis eenduidig kan worden vertaald in oplossingen. Voorbeelden die de onhoudbaarheid van dit verhaal onderstrepen, zijn legio. Controverses rond klimaatmodellen, vaccinaties, genetische modificatie en hydraulic fracking laten allemaal zien dat wetenschappelijke kennis op meerdere, soms onverenigbare, manieren wordt geïnterpreteerd, bekritiseerd, en vertaald in oplossingen en opties. Dit onhoudbare verhaal voedt steeds weer zowel de hoogmoed van de wetenschap als de verwachtingen van de maatschappij. Het leidt ook steeds tot teleurstelling bij de maatschappij over de niet ingeloste beloftes die zijn gedaan, en bij de wetenschap over de manier waarop maatschappelijke actoren, in plaats van de feiten, interpretaties en opties van wetenschappers over te nemen, hun eigen interpretaties verbinden aan kennis.

Hoe nu integer te handelen in dit mijnenveld? In mijn ogen ligt de oplossing niet in een reïncarnatie van het verlichtingsideaal, waarin de maatschappij weer opnieuw respect moet hebben voor de autonomie en autoriteit van wetenschap. En ook niet in een wetenschap die zich terugtrekt in de ivoren toren en de handen afhaalt van lastige trans-wetenschappelijke kwesties. Maatschappelijke en politieke legitimiteit zijn cruciaal en wetenschappers hebben de plicht om zich in te zetten voor de maatschappij en de democratie. Maar dit dient te gebeuren op een manier die ten volle erkent dat er niet zoiets is als waardevrije feiten ${ }^{3}$ (of feitenvrije waarden) en die niet vervalt in overmoed. We hebben een nieuw verhaal nodig en dit nieuwe verhaal draait wat mij betreft om integriteit. Voordat ik verder inga op wat dit zou kunnen betekenen geef ik een voorbeeld waarbij mijn werkgever, Wageningen University and Research (WUR), afgelopen jaar betrokken is geweest.

\section{Intermezzo: statiegeld}

Al sinds het verpakkingsbesluit van 2006 woeden er heftige discussies over hoe we moeten omgaan met plastic verpakkingen. Deze discussies gaan vooral over de 
keuze tussen twee opties: statiegeld of recycling. Voor en tegen beide opties wordt stevig gelobbyd door diverse actoren. Dit is de context waarin in 2009 WUR de opdracht kreeg om onderzoek te doen naar de kosten van statiegeld. Dit onderzoek heeft flink wat stof doen opwaaien. ${ }^{4}$ Nog voordat het rapport formeel was opgeleverd, deed staatssecretaris Atsma in maart 2012 een voorschot op de conclusie door te zeggen dat statiegeld peperduur was. Er volgde in maart 2014 een debatavond waarin ander onderzoek werd gepresenteerd dat aanleiding gaf tot een verschillende interpretatie van de kosten van statiegeld. Korte tijd later werden klachten ingediend over het WUR-onderzoek bij de Commissie Wetenschappelijke Integriteit van de WUR. Begin 2016 verscheen er een artikel in Trouw dat de onafhankelijkheid van het onderzoek bekritiseerde. In oktober 2016 spande WUR een rechtszaak aan tegen uitspraken van de Trouw-journalist

Deze zaak heeft geleid tot twee interessante uitkomsten: (1) de WUR-onderzoekers zijn door de Wageningse Commissie Wetenschappelijke Integriteit en het Landelijk Orgaan Wetenschappelijke Integriteit niet schuldig bevonden aan schendingen van wetenschappelijke integriteit, en (2) WUR heeft de rechtszaak tegen Trouw verloren. Deze uitkomsten zijn interessant, omdat ze op het eerste gezicht strijdig lijken. Kennelijk handelden de onderzoekers integer, maar mocht Trouw van de rechter toch zeggen dat het onderzoek gestuurd was. ${ }^{5}$ Diverse commentatoren van deze zaak gebruiken termen als onhandig of naïef om te karakteriseren wat hier is gebeurd. In het WUR-tijdschrift Resource schrijft Sikkema (2016) bijvoorbeeld: 'We zien vooral naïeve onderzoekers, handige bedrijven, en ambtenaren die aan damage control doen.'

Hoewel deze analyse zeker hout snijdt, is het de vraag of dit voldoende is. Termen als naïef hebben als gevolg dat het geheel kan worden afgedaan als een incidentele en individuele slordigheid en leiden de aandacht af van de institutionele en discursieve context waarin de relatie tussen beleid en maatschappij vorm krijgt. In dit geval was deze context zeer belangrijk. Dit onderzoek vond plaats in een bestaande controverse waarbij strijdende partijen wetenschappelijk onderzoek gebruiken om hun standpunten te onderbouwen. Het is niet verrassend dat dit ook in dit geval is gebeurd. De onderzoekers hebben een set feitelijkheden opgeleverd en deze feiten zijn samen met de onderzoekers, onbedoeld en onbewust, onderdeel van het politieke/maatschappelijke debat geworden.

Met dergelijk gebruik van wetenschap is in principe niks mis. Zoals ik al eerder zei, feiten zijn onvermijdelijk op verschillende manieren te interpreteren en kunnen worden gebruikt om verschillende standpunten te onderbouwen of juist te ondergraven. Dat is niet per se een kwestie van misbruik, fraude of manipulatie, want onderzoekresultaten kunnen niet alleen selectief worden gebruikt, ze zijn ook onvermijdelijk selectief. En deze selectiviteit is niet random of neutraal. Ze wordt bepaald in de vraagstelling van het onderzoek en die reflecteert altijd specifieke preferenties en waarden, van de onderzoeker, van de opdrachtgever of van de financier. Wiens waarden en preferenties die vraagstelling beïnvloeden, is daarmee, hoewel niet irrelevant, van ondergeschikt belang. De waardegeladen selectiviteit van onderzoek betekent dat alle wetenschappelijke kennis maatschappelijke en politieke implicaties heeft en dat dus alle onderzoekers, niet alleen in contractonderzoek maar ook in zogenaamd vrij of fundamenteel onder- 
zoek, zich moeten bezinnen op welke belangen en waarden ze bedienen en hoe daarvoor verantwoording kan worden afgelegd. ${ }^{6}$ Hoe dergelijke reflectie in de praktijk verschil kan maken, werk ik in de volgende paragraaf verder uit.

\section{Rollen van wetenschap}

Het statiegeldvoorbeeld is een voorbeeld van een klassieke opdrachtgeveropdrachtnemerrelatie. De gangbare taakverdeling in deze relatie is dat de opdrachtgever de vraagstelling formuleert en dat de opdrachtnemer feiten produceert om die vraag te beantwoorden. In de termen van Pielke (2007) speelt wetenschap dan de rol van scheidsrechter. Scheidsrechters kunnen goed uit de voeten met vragen die zodanig zijn geformuleerd dat ze door middel van feitelijkheden kunnen worden beantwoord. De vraag wat de kosten van statiegeld zijn, voldoet daaraan. ${ }^{7}$ De scheidsrechter functioneert goed in vraagstukken waar consensus is over problemen, oplossingen en benodigde kennis. Met andere woorden, in goed gestructureerde problemen (Hisschemöller \& Hoppe,1996; In 't Veld, 2000). Wetenschappelijke onafhankelijkheid in deze rol betekent dat de onderzoeker alleen de feiten levert en geen eigen normen en waarden daaraan verbindt. Dit is de rol waar wetenschappers zich vaak het prettigst bij voelen en die meestal ook de voorkeur heeft van opdrachtgevers. Maar wetenschap is in deze rol niet neutraal. De opdrachtnemer aanvaardt namelijk met de opdracht ook het normen-enwaardenkader van waaruit de vraagstelling tot stand is gekomen. Zolang er over dat kader geen expliciete discussies zijn, blijft dit vaak onzichtbaar en kan de rol van de onderzoeker als scheidsrechter ook legitiem zijn. Echter, bij openlijke controverse, of als er machtsongelijkheid is waarbij één normen-en-waardenkader dominant is, verliest deze rol aan effectiviteit en legitimiteit. Ofwel omdat wetenschap, zoals het statiegeldvoorbeeld laat zien, onderdeel wordt van de controverse, ofwel omdat ze onterecht dominante belangen dient en minder geprivilegieerde actoren uit het oog verliest of zelfs benadeelt.

Wetenschappers kunnen op legitieme wijze expliciet partij kiezen en kennis ontwikkelen die aansluit bij specifieke normen-en-waardenkaders. Dit kan spelen bij zowel zogenaamd vrij en fundamenteel onderzoek als bij opdrachtonderzoek. Veel ecologisch of natuuronderzoek wordt vormgegeven vanuit het, vaak diepgevoelde, belang van natuur en natuurbescherming. Bij antropologisch of ontwikkelingsgericht onderzoek speelt vaak iets vergelijkbaars, maar dan met betrekking tot gemarginaliseerde actoren. ${ }^{8}$ Vaak wordt dergelijke kennis ook nog vertaald in concrete aanbevelingen voor beleid of beheer om natuurkwaliteit te verbeteren of de positie van bepaalde actoren te versterken. Deze rol wordt door Pielke (2007) de pleitbezorger genoemd. Een pleitbezorger verbindt wetenschappelijke kennis aan een bepaalde geprefereerde oplossing. Onafhankelijkheid in deze rol betekent dat onderzoekers hun eigen normen-en-waardenkaders volgen en daarin niet beïnvloed zijn door anderen. Deze rol kan zeker legitiem zijn, bijvoorbeeld in situaties waarbij er een noodzaak is om dominante machtsverhoudingen en discoursen open te breken of in bestaande controverses bepaalde partijen te versterken. De rol van pleitbezorger heeft een slechte naam omdat hij vaak in verband wordt 
gebracht met de manipulatie van feiten voor politieke doeleinden. Ik ontken niet per se dat dat gebeurt (en kwalijk is), maar het moet worden benadrukt dat wetenschap in deze rol niet per se meer of minder politiek of neutraal is dan in de rol van scheidsrechter.

Omdat waardevrije kennis niet bestaat en omdat je erop kunt rekenen dat in controverses deze waarden ook expliciet zullen worden gemaakt, is het moeilijk om te voorkomen dat wetenschap onderdeel van het debat wordt. Een zinvolle optie kan dan zijn om op basis van een breed palet aan perspectieven, preferenties en waarden kennis te verzamelen en handelingsopties te ontwikkelen. Deze rol wordt ook wel de (kennis)makelaar genoemd (Pielke, 2007). Onafhankelijkheid in deze rol krijgt vorm via de expliciete inzet om diversiteit te waarborgen. In het statiegeldvoorbeeld zou deze rol aantrekkelijk kunnen zijn geweest. Echter, hij is niet makkelijk te realiseren. Onderzoekers kunnen dan onder andere niet zomaar een vooraf bepaalde vraagstelling accepteren. De vraag 'wat zijn de kosten van statiegeld' kan dan wel een onderzoekbare vraag zijn, maar hij is ook smal en onevenwichtig. Een makelaar moet eerst in onderhandeling met de opdrachtgever of de financier om te kijken of deze vraag verbreed kan worden, bijvoorbeeld door ook naar recycling te kijken of door niet alleen naar kosten maar ook naar milieueffecten of maatschappelijke acceptatie te kijken. Daarna moet de kennismakelaar actief op zoek gaan naar de verschillende perspectieven op problemen en oplossingen die leven in de maatschappij en deze in het onderzoeksproces betrekken. De uitkomst van dit proces is een set opties of oplossingen die rekening houden met de verschillende preferenties van maatschappelijke actoren en die op een evenwichtige manier kunnen worden afgewogen. Behalve dat dit een behoorlijke investering vraagt in de relatie tussen opdrachtgever en onderzoeker en tussen onderzoeker en andere maatschappelijke actoren, is deze rol afhankelijk van de bereidwilligheid van deze actoren om mee te werken. Ook in deze rol is wetenschap niet immuun voor kritiek. Alleen al ervoor pleiten om ook andere perspectieven in het onderzoek te betrekken is een poging om bestaande machtsverhoudingen en discoursen open te breken en kan dus aanleiding zijn om onderzoekers te bekritiseren als pleitbezorger van deze andere perspectieven.

Deze bespreking van rollen maakt duidelijk dat in de relatie tussen wetenschap en maatschappij onderzoekers meerdere mogelijkheden hebben dan alleen de traditionele scheidsrechterrol. Deze rollen zijn geen van alle waardevrij, zoals ik al eerder zei is schone handen houden geen levensvatbare optie, maar ze bieden wel mogelijkheden voor vormen van onafhankelijkheid en integriteit die passen bij verschillende soorten maatschappelijke en beleidsvraagstukken en problemen.

\section{Integere relaties}

Zodra je wetenschappelijke integriteit in een bredere context plaatst en verbindt aan de relatie tussen wetenschap en maatschappij, stijg je uit boven het niveau van individuele onderzoekers: dit is niet een kwestie van integer handelen, maar van integere relaties. De huidige codes en principes voor wetenschappelijke integriteit zijn daarmee ook niet toereikend, want die richten zich vooral op individu- 
eel gedrag en op de uitvoering van onderzoek. Wellicht verheldert dat ook de schijnbaar tegenstrijdige uitkomsten van de statiegeldzaak: het onderzoek was wellicht integer uitgevoerd, maar dat wil nog niet zeggen dat het ook integer onderzoek was. Voor wetenschappelijke integriteit moet het niet alleen gaan om 'doing things right', maar ook om 'doing the right things'. ${ }^{9}$ Vooral dit laatste punt vraagt om een bredere discussie binnen universiteiten en maatschappelijke organisaties. We moeten de juiste randvoorwaarden creëren om ervoor te zorgen dat de vraag of we wel de juiste dingen doen, kan worden gesteld en, want daar kan het niet bij blijven natuurlijk, dat de consequenties van het antwoord ook genomen kunnen worden. Soms zal dit bijvoorbeeld financiële consequenties kunnen hebben als een onderzoeksopdracht wordt afgewezen, of het kan zijn dat bepaalde onderzoeksopdrachten worden aanvaard die bepaalde belangrijke partners niet zinnen. Niet alle onderzoeksvragen verdienen wetenschappelijke inzet; soms moeten machtsblokken doorbroken worden en soms moet wetenschap openlijk partij kiezen (wellicht ten overvloede: niet openlijk partij kiezen is niet hetzelfde als geen partij kiezen en is ook niet hetzelfde als waardevrij onderzoek doen).

Zoals ik eerder aangaf, ligt het antwoord voor de huidige crisis in de wetenschap niet in een nieuwe Verlichting en ook niet in een wetenschap die zich terugtrekt in de ivoren toren. Het oude verhaal over waardevrije kennis en eenduidige oplossingen heeft geleid tot overmoed, controverse en teleurstelling en is niet langer houdbaar. Waardevrije kennis bestaat niet en de enige keuze die wetenschap dus heeft is om bewust, reflexief en transparant met waarden om te gaan. Integere wetenschap is onderdeel van en draagt zorg voor integere relaties. Ze moet haar rol zorgvuldig spelen op een manier die rekening houdt met de context waarin wetenschap wordt geproduceerd en gebruikt. Ze moet daarin onafhankelijkheid hoog in het vaandel houden, en tegelijkertijd erkennen dat verschillende invullingen van onafhankelijkheid mogelijk zijn, en ze dient verantwoording af te leggen voor de gemaakte keuzes en voor de consequenties van die keuzes.

\section{Noten}

1 Volgens Latour (2013), zijn deze parallellen niet toevallig: net als in de zeventiende eeuw bevinden we ons in een staat van crisis, met voortdurende strijd om feiten en waarin we ons tot de wetenschap richten in de zoektocht naar gezamenlijke waarheid. Latour vindt dit geloof in wetenschap als instrument voor verzoening een vergissing en in plaats daarvan pleit hij voor diplomatie die rekening houdt met onverenigbare tegenstellingen.

2 Vergelijkbare pleidooien zijn te vinden in het werk van Funtowicz en Ravets (1993) rond Post Normal Science.

3 Binnen de wetenschap en de wetenschapsfilosofie is dit geen onderwerp van serieus debat. Het epistemologische argument hiervoor is onbetwist en zal ik niet herhalen.

4 In de bespreking van dit voorbeeld baseer ik me uitsluitend op de informatie die op internet beschikbaar is. 
5 Ik wil benadrukken dat ik geen een oordeel vel over de acties van de onderzoekers en Trouw, noch over de oordelen van de Wageningse Commissie voor Wetenschappelijke Integriteit, het Landelijk Orgaan Wetenschappelijke Integriteit en de rechter. Het gaat er mij om wat we van deze zaak kunnen leren over integriteit en de relatie tussen kennis en maatschappij.

6 Dit argument komt uit mijn inaugurele rede: 'the political implications of scientific knowledge imply a need for critical scrutiny of the interests that science serves and fails to serve as well as mechanisms to ensure the accountability of science' (Turnhout, 2016).

7 Deze vraag leid ik af uit het eindrapport (Thoden van Velzen \& Bos-Brouwers, 2012). De opdrachtbrief is niet openbaar.

8 Hier worden vaak participatieve methoden toegepast die uitgaan van de behoeften van lokale actoren. Dat maakt de rol eerder een van partnerschap, of 'participatory expert' (Broekhans \& Turnhout, 2012; Turnhout e.a., 2013) dan pleitbezorger.

9 Deze parafrasering komt uit Drucker (1993).

\section{Literatuur}

Benedictus, R., Miedema, F., \& Ferguson, M.W.J. (2016). Fewer numbers, better science. Nature, 538: 453-455.

Broekhans, B., \& Turnhout, E. (2012). Roles of environmental experts in practice. In: W. Tuinstra e.a. (red.), Environmental problems: Crossing boundaries between science, policy and society (Open University cursusboek). Heerlen: Open Universiteit, 89-105.

Bush, V. (1945). Science: The endless frontier. Washington DC: Us Government Printing Office.

Dijck, J. van, \& Saarloos, W. (2017, 2 januari). Wetenschap is niet 'maar een mening'. NRC.

Drucker, P. (1993). Management: Tasks, responsibilities, practices. New York: HarperBusiness.

Funtowicz, S.O., \& Ravetz, J.R. (1993). Science for the post normal age. Futures, 25: 739-755.

Gibbons, M. (1999). Science's new social contract with society. Nature, 402: c81-c84.

Halffman, W., \& Radder, H. (2013). Het academisch manifest: van een bezette naar een publieke universiteit. Krisis, tijdschrift voor actuele filosofie, 3: 2-18.

Hisschemöller, M., \& Hoppe, R. (1996). Coping with intractable controversies, the case for problem structuring in policy design and analysis. Knowledge and Policy: the international journal of knowledge transfer and utilization, 8 (4): 40-60.

Jasanoff, S. (2003). Technologies of humility: Citizen participation in governing science. Minerva, 41: 223-244.

Latour, B. (2013). Facing Gaia. Six lectures on the political theology of nature. The Gifford lectures on natural religion. Edinburgh.

Nurse, P. (2012). The new enlightenment. The Richard Dimbledy lecture. https:// royalsociety.org/ /media/Royal_Society_Content/people/fellows/2012-02-29Dimbleby.pdf.

Pielke, R. (2007). The honest broker making sense of science in policy and politics. Cambridge: Cambridge University Press.

Polanyi, M. (1962). The republic of science, its political and economic theory. Minerva, 1: 54-73.

Sarewitz, D. (2016). Saving science. The New Atlantis, 49: 4-40. 
Shapin, S., \& Schaffer, S. (1985). Leviathan and the air-pump: Hobbes, Boyle and the experimental life. Princeton: Princeton University Press.

Sikkema, A. (2016). Statiegeldonderzoek was integer en ondermaats. Resource.

Thoden Van Velzen, E.U., \& Bos-Brouwers, H.E.J. (2012). Analyse Nederlands statiegeldsysteem voor pet flessen: studie naar kosten, materiaalgebruik en energiegebruik van het Nederlandse statiegeldsysteem voor frisdrank- en waterflessen (rapport nr. 1316B). Wageningen UR Food \& Biobased Research.

Turnhout, E. (2016). The politics of environmental knowledge. Inaugural lecture upon taking up the position of personal professor at Wageningen University. Wageningen.

Turnhout, E., Stuiver, M., Klostermann, J., Harms, B., \& Leeuwis, C. (2013). New roles of science in society: Different repertoires of knowledge brokering. Science and Public Policy, 40: 354-365.

Veld, R.J. in 't (2000). Willens en wetens: de rollen van kennis over milieu en natuur in beleidsprocessen. Utrecht: Lemma.

Weinberg, A.M. (1972). Science and trans-science. Minerva, 10: 209-222. 